\title{
RESEARCH
}

\section{APPROACH TO CUTANEOUS LESIONS OF THE HEAD AND NECK IN THE GERIATRIC AGE GROUP: RETROSPECTIVE ANALYSIS OF 170 CASES}

Turkish Journal of Geriatrics DOI: 10.31086/tjgeri.2020.155 2020; 23(2): 206-215

- Müge ÖZÇELIK KORKMAZ1

- Bahar SEVIMLI DikicieR² (D

- Melike BAHÇECITAPAR ${ }^{3}$ (D)

- Sena GENÇ ELDEN ${ }^{1}$ (D)

- Mehmet GÜVEN ${ }^{1}$ D

CORRESPONDANCE

Müge Özçelik KORKMAZ

Sakarya University, Training and Research Hospital, Otorhinolaryngology Department, Sakarya, TURKEY.

Phone: +90530820173

e-mail: ozcelikmuge@gmail.com

Received: February 11, 2020

Accepted: April 20, 2020

Sakarya University Training and Research Hospital, Otorhinolaryngology Department, Sakarya, TURKEY

2 Sakarya University Training and Research Hospital, Dermatology Clinic, Sakarya, TURKEY

${ }^{3}$ Hacettepe University Science Faculty, Statistics Department, Ankara, TURKEY

\section{Abstract}

Introduction: The incidence of skin lesions increases with advancing age, especially in the head and neck region. The aim of this study was to evaluate the demographic data of head and neck skin lesions in the geriatric age group and the preferred surgical approaches.

Material-Method: The records of 170 patients of an age $>65$ years who underwent surgical excision and reconstruction for head and neck lesions in our clinic were retrospectively reviewed. The histopathological results of the lesions and the repair method used were evaluated according to age and localization.

Results: The mean age of the patients was $71.42 \pm 14.20$ years. The histopathologic distribution of the lesions were 75 (44.2\%) basal cell carcinoma, $30(17.6 \%)$ squamous cell carcinoma and 65 (38.2\%) benign. The most frequent localizations were nose and cheeks, and the most preferred reconstruction methods were primary closure and advancement flap. None of the patients had serious complications.

Conclusion: Basal cell carcinoma is the most common lesion in the head and neck region in elderly individuals. The lesions in this region can be detected in the early stage since they are in the visible region. The Surgical excision and repair with local flaps in the treatment provide very successful cosmetic results.

Keywords: Skin Neoplasm; Aged; Head neck surgery. 


\section{INTRODUCTION}

Skin lesions are frequently encountered in the geriatric population, especially in the head and neck regions, due to the skin ageing. Even though these lesions are often benign, it is widely known that the prevalence of cutaneous malignant lesions increases with age (1). In this respect, the most frequent malignant pathology is basal cell carcinoma (BCC), followed by squamous cell carcinoma (SCC), and malignant melanoma (MM). The long-term exposure of the head and neck regions to the ultraviolet (UV) rays is an essential risk factor for the development of skin cancer in the geriatric patients (2). BCC and SCCs are often observed as local invasive ulcers (3). The treatment options for the skin lesions in this region are surgical excision, medical immunomodulator creams, cryotherapy, cauterisation and photodynamic therapy $(4,5)$. After the detection of affected region, the defect is repaired by using primary repair, local flaps, or free tissue grafts in the excision process (6). The skin elasticity is high in the elderly population, which allows the defects to be repaired with primary and local skin flaps. Additionally, in order to avoid possible complications of general anaesthesia, it is advantageous to perform such operations with local anaesthesia in this age group.

Although there are studies on the skin diseases in the elderly population in the literature, detailed studies on the surgical results of lesions in the head and neck regions in this age group are very few $(7,8)$. The purpose of this study is to evaluate and analyse the demographic data and surgical reconstruction methods employed for the geriatric patients who underwent surgery for the treatment of skin lesions that were located in the head and neck regions.

\section{MATERIALS AND METHOD}

In this study, we retrospectively analysed the medical records of 170 patients who are older than 65 years and underwent the excision of skin lesions in the head and neck regions (excluding the lips) in Sakarya University Medical Faculty ENT clinic between January 2015 and March 2019 were. The ethical approval of study was obtained from the ethics committee of Sakarya University Medical Faculty (715224473/050.01.04. Date : 02.12.2019).All the patients included in the study had a follow-up period of longer than six months after excision. In addition, we also examined the initial examination findings, age, gender, area of lesion, long diameter, surgical repair technique, histopathological findings, complications, postoperative follow-up duration and recurrence data.

Before the surgery, all the patients received dermatologic consultation, and a diagnostic punch biopsy was performed on the suspected lesions. Based on the histopathological diagnosis, patients with suspected metastatic lymph nodes underwent neck ultrasonography examinations. According to the histopathologic diagnosis, the lesions were categorised into three subgroups: benign, BCC and SCC. The histopathological diagnosis of the patients was statistically analysed according to age, gender and regional distribution. The participants in the study were also divided into two age groups: between 65 and 75 years and older than 76 years. The lesions were grouped according to the size: greater than $1 \mathrm{~cm}, 1-2 \mathrm{~cm}$ and greater than $2 \mathrm{~cm}$. In terms of localisation, the head-neck region was further divided into eight basic subunits: the facial area, forehead, nasal unit, upper and lower eyelid units, cheek unit, perioral unit, mentum unit, auricular unit, and neck (9). This study did not include the lesions on the lip because they require different treatment and surgical repair principles. The defect repair techniques employed in this study were recorded as primary closure, advancement flap (single/bilateral, V-Y), rotation flap (Figure 1), transposition flap (bilobed and rhomboid flaps), interpolation flap (nasolabial, forehead), free flap and Z-plasty. 


\section{Operative Techniques}

All the patients provided their detailed consent. The examination of excision technique records revealed that if the pre-diagnosis was benign, then it was normal skin margin of 1-2 $\mathrm{mm}$; if the prediagnosis was BCC, then the normal skin margin was of $4 \mathrm{~mm}$; and if the pre-diagnosis was SCC, then the normal skin margin was of 7-10 $\mathrm{mm}$. The size and localisation of the lesion determine the basic excision principle for these cases. Full-thickness excision including the lesion with a number of 15 scalpels had been noted in the records. Suturing data for closure had been recorded as $3 / 0$ vicryl, and 4/0-5/0 prolene sutures were used. According to the file records of patients, the postauricular area and the supraclavicular region were mostly preferred for free skin grafts. The applied surgical method is provided in detail in the medical files of each patient.

\section{Postoperative Follow-up}

All the patients underwent postoperative follow-up under the supervision of physicians in our clinic. The patients were mostly discharged on the first postoperative day, which was recorded on the medical file. Each patient had been recalled to the clinic on the second postoperative day or at seventh or tenth postoperative days for the removal the sutures according to the charts. All patients had been re-evaluated for an average of four to six weeks based on their histopathological diagnosis. The cosmetic outcomes were evaluated at the end of the sixth month to obtain clearer results. The follow-up and planning of each patient had been managed according to the histopathological diagnosis, complications and excision margins.

\section{Statistical Analysis}

We used descriptive statistics, such as mean (SD) and distribution for the analysis of patients' characteristics. The categorical data were provided as numbers ( $n$ ) and percentages (\%). The Kolmogorov-Smirnov test was performed for the normality distribution analysis, whereas the nonparametric tests were conducted according to the results. The categorical variables were compared by the chi-square test. A correspondence analysis was undertaken to determine the treatment techniques utilised for the lesions according to localisation. In addition, $\mathrm{p}$ values less than 0.05 were accepted as significant. All the statistical analyses were performed by using the commercial software (IBM SPSS Statistics. Version 23.0. Armonk. NY: IBM Corp.)

Table 1. General data and characteristics of patients and lesions.

\begin{tabular}{|c|c|c|}
\hline Parameter & n (\%) & $\mathbf{P}$ \\
\hline Gender & $\begin{array}{r}69(40,6) \\
101(59,4)\end{array}$ & 0,711 \\
\hline $\begin{array}{r}65-75 \\
>75\end{array}$ & $\begin{array}{l}98(57,64) \\
72(42,34)\end{array}$ & 0,056 \\
\hline $\begin{array}{r}\text { Benign } \\
\text { BCC } \\
\text { SCC }\end{array}$ & $\begin{array}{l}65(38,2) \\
75(44,1) \\
30(17,6)\end{array}$ & 0,197 \\
\hline $\begin{array}{l}\text { Lesion Localization } \\
\qquad \begin{array}{r}\text { Forehead } \\
\text { Nasal } \\
\text { Eyelid } \\
\text { Cheek } \\
\text { Perioral } \\
\text { Mentum } \\
\text { Auricula } \\
\text { Neck }\end{array}\end{array}$ & $\begin{array}{r}15(8,8) \\
50(29,4) \\
10(5,9) \\
34(20,0) \\
16(9,4) \\
5(2,9) \\
26(15,3) \\
14(8,2)\end{array}$ & $0,001^{*}$ \\
\hline $\begin{array}{l}<1 \mathrm{~cm} \\
1-2 \mathrm{~cm} \\
>2 \mathrm{~cm}\end{array}$ & $\begin{array}{l}72(42,4) \\
63(37,1) \\
35(20,6)\end{array}$ & $0,000^{\star \star *}$ \\
\hline
\end{tabular}

*Statistically significant difference considering the localization distribution of lesions

**Statistically significant difference considering the size of lesions 


\section{RESULTS}

\section{General Patient Data}

Table 1 presents the descriptive data of 170 patients included in the study. The total number of female patients was $69(41 \%)$, whereas the number of male patients was 101 (59\%). The overall mean age of the patients was $71.42 \pm 14.20$ years (min 65-max 88). Furthermore, 98 patients (57, 64\%) were between 65 and 75 years, whereas 72 patients $(42,35 \%)$ were older than 76 years. There was no statistically significant difference between the female and male patients in terms of age distribution ( $p>0.05)$. The mean follow-up period was $26 \pm 12,36$ ( $\min 12-\max 48)$ months. According to the regional distribution of the lesions, the most frequent localisation was observed in the nasal ( $\mathrm{n}$ $=50 ; 29.4 \%)$, cheek $(n=34 ; 20 \%)$, and auricular ( $n$ $=26 ; 15.3 \%$ ) units. The mean size of the lesions was $1.78 \pm 1.02 \mathrm{~cm}(\min 0.3 \mathrm{~cm}-\max 7 \mathrm{~cm})$. When the lesion size was evaluated according to the long diameter, 62 (36.47\%) patients had a lesion size smaller than $1 \mathrm{~cm}, 73$ (42.94\%) patients had a lesion size of $1-2 \mathrm{~cm}$, and 35 (20.58\%) patients had a lesion size larger than $2 \mathrm{~cm}$ (Table 1).

\section{Histopathological Results}

The histopathological data revealed that BCC was diagnosed in 83 cases (48.88\%), SCC in 32 (18.8\%), and some benign pathologies in 55 cases (32.35\%). The most common diagnosis among the benign lesions was nevus that had been reported in 12 patients, followed by keratoacantoma in nine patients, actinic keratosis in eight patients, lentigo simplex in seven patients, verruca vulgaris in seven patients, and atypical polypoid tubular apocrine adenoma, calcified trichilemmalcyst, angiofollicular hyperplasia, dermatofibroma, pilomatrixoma and epidermal inclusion cyst in one patient each. Lymph node metastasis was not recorded in the patients who had malign diagnosis. The mean age of the patients with a benign diagnosis was statistically significantly lower $(p=0.023)$. Age did not statistically significantly differ between the patients with different malignant diagnoses (SCC or BCC) ( $p=0.647)$. While there was no significant difference in the malignant and benign diagnosis rates in women $(p=.07)$, a significant difference was observed in the male patients in the favour of malignancy $(p=0.01$ ) (Table 2).

The evaluation of the distribution of diagnoses among the eight subunits determined that the lesions with a diagnosis of BCC were more predominantly located in the second and fourth regions than in the remaining regions $(p=-0.003)$,

Table 2. According to histopathological results of the lesions, sex, age, regional placement frequency and average size are specified.

\begin{tabular}{|c|c|c|c|c|}
\hline Parameter & Benign & $\mathrm{BCC}$ & SCC & $\mathbf{P}$ \\
\hline $\begin{array}{r}\text { Gender }(\mathrm{n}, \%) \\
\text { Male } \\
\text { Female }\end{array}$ & $\begin{array}{l}29(52,72) \\
26(47,27)\end{array}$ & $\begin{array}{l}46(55,42) \\
37(44,57)\end{array}$ & $\begin{array}{l}21(65,62) \\
11(34,37)\end{array}$ & $\begin{array}{r}023^{\star} \\
.083\end{array}$ \\
\hline Age & $66,25 \pm 20,84$ & $76,83 \pm 12,71$ & $77,67 \pm 14,00$ & $032^{\star *}$ \\
\hline Localization(n,\%) & $\begin{array}{r}\text { Nasal }(14,21.5) \\
\text { Cheek }(14,21.5)\end{array}$ & Nasal $(28,56)$ & Perioral $(9,56,2)$ & $\begin{array}{l}003^{\star \star \star} \\
.004^{\star \star \star}\end{array}$ \\
\hline $\begin{array}{l}\text { Diameter }(\mathrm{mm}) \\
\text { (Mean } \pm \text { St.Deviation }\end{array}$ & $1,66 \pm 1,27$ & $1,46 \pm 0,86$ & $1,71 \pm 0,75$ & 0,197 \\
\hline
\end{tabular}

*Statistically significant difference considering the gender distribution of malignancy ** Statistically significant difference considering the mean age for benign pathologies *** Statistically significant difference considering the most frequent localization 
and the SCC diagnosis was more frequent in the fifth region ( $p=0.004)$. The lesions diagnosed as benign were mostly located in the nasal unit $(21.5 \%)$ and in the cheek (21.5\%). There was a significant difference between the malignant and benign diagnoses in terms of lesion diameters. Most of the patients diagnosed with benign lesions had the diameter of these lesions to be $2.00 \mathrm{~cm}$ and over. In total, $65 \%$ of the patients diagnosed with BCC had a lesion size in the range of 1-2 $\mathrm{cm}$, whereas this value was less than $1.00 \mathrm{~cm}$ in $30 \%$ of those diagnosed with SCC $(p=0.019)$. The diameter of lesions in the cheek and forehead was significantly greater than the remaining regions ( $p$ =0.001). (Table 2)

\section{Surgical approach}

The surgical repair methods that had been preferred after excision were as follows: primary closure in 62 patients (36.5\%), advancement flaps in 24 (14.1\%), rotation flaps in 44 (25.9\%), transposition flaps in 28 (16.4\%), free flaps in 4 (2.4\%), interpolation flaps in 4 (2.4\%), and Z-plasty in $4(2.4 \%)$. By considering the age distribution of the patients, the mean age of the patients that underwent primary closure was statistically significantly higher $(p=0.001)$ (Table 3). According to the results of correspondence analysis, there was a significant relationship concerning the preferred reconstruction method according to the region of the lesions ( $p=0.005)$. In the nasal lesions, transposition flaps (bilobed) were used at a statistically significant rate $(p=0.003)$. In mentum and neck regions, the lesions had been treated with the primary closure technique. Another notable finding of the analysis stated that free and interpolation flaps had been mostly utilised for the ear and nose regions. There was no significant difference in the distribution of the remaining method according to the lesion localisation.

Figure 2 presents the results of the correspondence analysis of 'procedure', which represents the treatment technique applied to the lesions, and 'localisation', which refers to the subunit on which the lesion was located.

\section{Complications}

Recurrence was not recorded in the patients with malignant lesions during the follow-up of a maximum period of 48 months. Complication data were not observed except for partial necrosis in $11(6.47 \%)$ patients ( 5 females and 6 males). In fact, these cases showed improvement with postoperative debridement and wound care. Additionally, according to the data in the patient files, flap losses, which would require the repetition of flap repair, were not observed. Functionally, in the cases where the eyelid was involved, no ectropion had been occurred, and the margins were recorded as well aligned and stable which had been explained as 'adequate eyelid closure, without any exposure sequelae'.

Table 3. Distribution of surgical repair methods by regions and age.

\begin{tabular}{|c|c|c|c|}
\hline Surgical Technique & n (\%) & Age (Mean \pm St.Deviation) & $P$ \\
\hline \multicolumn{4}{|l|}{ Primary Closure } \\
\hline Advancement flaps & $62(36,5)$ & $78,02 \pm 21,27$ & \\
\hline Rotation flap & $24(14,1)$ & $69,38 \pm 17,13$ & \\
\hline Bilobe flap & $44(25,9)$ & $70,11 \pm 8,74$ & \\
\hline Free flaps & $28(16,5)$ & $66,46 \pm 17,16$ & \\
\hline \multirow[t]{2}{*}{ z- plasty } & $8(4,7)$ & $68,00 \pm 5,98$ & \\
\hline & $4(2,4)$ & $73,50 \pm 5,75$ & $.001 *$ \\
\hline
\end{tabular}

*Statistically significant considering the age distribution 
Figure 1. Rotation flap design for the lesion located on the nasal dorsum.

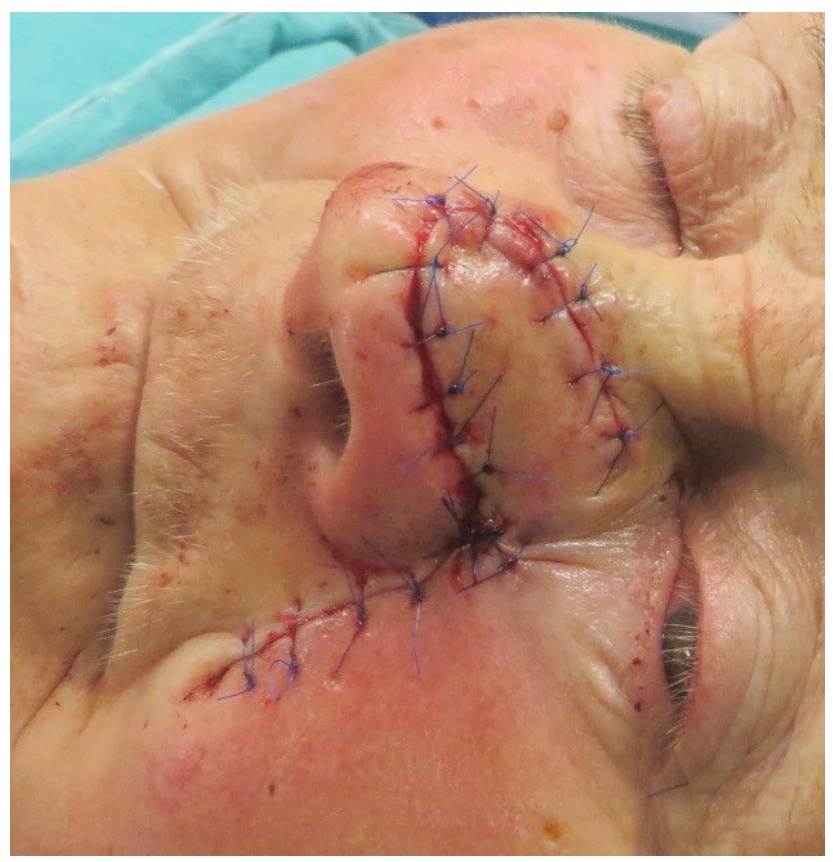

Figure 2. Frequency of surgical repair methods according to regions.

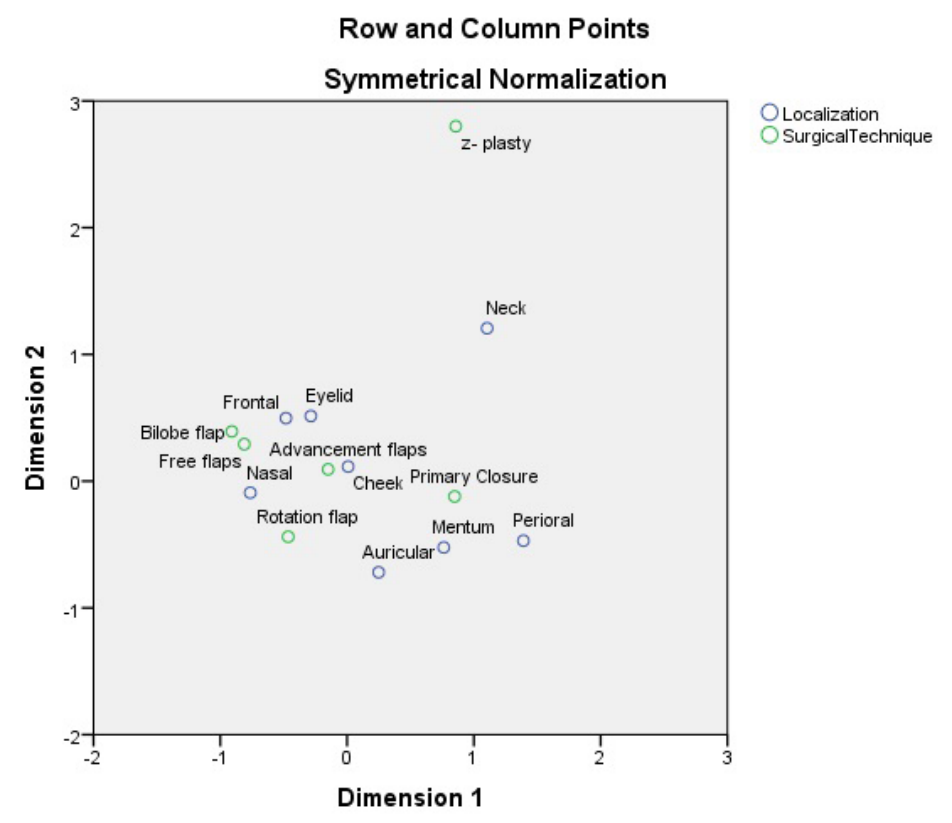




\section{DISCUSSION}

The incidence of skin lesions increases with age as it depends on the long-time UV exposure, especially at head and neck regions (4). Although the skin cancer rates of elderly patients have been reported between 9 and 12\% in the studies conducted in the dermatology clinics, it is difficult to accurately determine the incidence of skin cancer in this age group $(10,11)$. This may be due to the fact that patients presenting for suspicious skin lesions are not directed to surgical excision, which led to the avoidance of possible complications; hence, the differential diagnosis of benign lesions is not possible. In this study, we analysed the data of 170 geriatric patients who had undergone surgery for skin lesions located in the head and neck regions in our otolaryngology clinic. The most common histopathologic diagnosis was BCC in our study group, which was consistent with the literature (11). In the cohort studies, a high increase in the incidence of BCC had been reported in white patients over 65 years. Again, more than $80 \%$ of cutaneous SCC cases occur in the elderly patients and the average age at diagnosis is 70 years (12). Benign pathologies were detected in $32.35 \%$ of the patients included in our study, and the most common diagnosis was nevus. Even so, it was noteworthy that our sample included rare benign pathologies, such as tubular apocrine adenoma, calcified trichilemmal cyst, angiofollicular hyperplasia and pilomatrixoma. The mean age of the patients with a malignant diagnosis in our study group was statistically significantly higher $(p=0.001)$. From a gender point of view, the rate of malignant diagnosis was significantly higher in men $(p=0.01)$, which is a consistent finding in the literature $(7,11,12)$.

SCCs occurring at the head and neck regions and lymph node metastases are at a higher risk of recurrence than SCCs located on the trunk and extremities $(13,14)$. BCCs of the head and neck are also more likely to recur than those on the trunk and extremities. BCCs are much less likely to metastasise than SCC (15). In our study, none of the patients with malignancies were diagnosed with lymphoid and distant metastasis.

We also evaluated whether the excised lesions were different in the regional distribution according to the histopathological diagnosis because in the literature, there is no similar grouping for the head and neck regions in this age group. The diagnosis of BCC was found to be significantly higher in the nasal and cheek areas $(p=0.003)$. This was considered to be due to the more protruding characteristics of these locations and the longer exposure to the sun with age. Although there is no similar study in this age group, Dalal et al. reported the most common localisation for BCC as the nose and cheek regions in their study (16). Concerning the rate of SCCs, a significantly higher number of lesions were located in the perilabial region $(p=0.004)$. Although the lip lesions were excluded from our study, the diagnosis of SCC, which was predominant around the lip region, presents similar data to lip cancer (17).

Medical treatments may be the first choices in the elderly patients for the treatment of head and neck lesions. However, as it is believed, surgical excision is not as difficult and complicated. To minimise the cosmetic deformities, local flaps serve as a good alternative in the head and neck regions. The four basic factors should be considered in the surgical treatment: total removal of the tumour or lesion, maximal preservation of normal tissue, preservation of function and optimal cosmesis (18). Even if the lesion diameter is large in certain regions, the elasticity of skin tissue allows for primary repair in elderly patients. In our study group, it was observed that primary repair was the reconstruction method used as the first choice, especially in the cheek and neck areas $(p=0.004)$. Although, the excision and repair of periorbital lesions may result in an increased risk of ectropion in the elderly patients, other similar studies have showed that the most challenging region was the auricle $(19,20)$. For 
these areas, the more preferable methods are pedicle flaps, free flaps or pedicle flaps extended from the postauricular region. In our study group, free flaps were used in the repair of 2 of the 26 auricular lesions, whereas the advancement flaps were preferred for the lesions on the helix and postauricular pedicle flaps for those located in the cavum conchae region. Bilobed flaps are easy to apply and very effective in the closure of the defected area in the nasal lesions (21). Similarly, in this study, these flaps were more utilised in the nasal region. The advancement flap design is relatively simple and can be successfully applied to repair a wide variety of small- or moderate-sized cheek defects (22). This group of flaps is based on an incision that allows the "sliding" movement of the tissue. In particular, the $\mathrm{V}-\mathrm{Y}$ advancement flap is equally effective for the coverage of large cheek wounds and small defects of those approximating the lid or lateral cheek (23).

The most important advantage of local flaps is that they do not cause any secondary morbidity by allowing the simultaneous closure of the defect and flap donor area usually under the local anaesthesia. In order to prevent the complications of general anaesthesia due to concomitant diseases in elderly patients, it is advantageous to administer local anaesthesia.

All the patients in our study group received dermatologic consultation before excision. The lesions that were clinically suspected of malignancy or had signs of malignancy in the punch biopsy were referred to be surgically excised. Therefore, the mean lesion diameter was relatively small, which was attributed to the consultation provided to the patients at an early stage. We also investigated the relationship between the lesion diameter and the regional distribution of lesions and diagnoses, which was quite different from the literature. According to the results, the rate of malignancy increased $(p=0.001)$ with the decrease of lesion diameter. Furthermore, the lesions located in the cheek and forehead subunits were found to be larger than those in the remaining subunits $(p=0.001)$. It is also noteworthy that the patients reported no cosmetic dissatisfaction and no recurrence occurred in the long-term period. In similar studies conducted with local flaps, it was emphasised that the cosmetic expectations of the patients were well satisfied (24).

An observational study reported complications in $7.9 \%$ of 247 patients over 85 years of age who underwent surgery for cutaneous lesions (24). No major complications were observed in our study, except for local necrosis, and the complication rate $(6.47 \%)$ was consistent with the literature. In a review, for a group of patients older than 75 years, male gender, histologic type and inadequate initial resection were identified as the high risk factors for complications (25). Additionally, the high rates of anticoagulation use and the possibility of comorbidity such as diabetes may increase the likelihood of bleeding and infection of surgical area in the postoperative period. No serious complications were observed in our patient group. There are no reports directly comparing the postoperative complications of cutaneous surgery between older and young patients in literature. Our study also contributes to the literature regarding the complication rates, which is not significantly different in the elderly patients.

\section{CONCLUSIONS}

Cutaneous head and neck lesions are the primary diseases of the geriatric population. General physicians, dermatologists and otorhinolaryngologists dealing with geriatric patients frequently encounter this condition. Most head and neck cutaneous lesions are relatively small, but the excision is often required in this age group due to the high risk of malignancy. Although there are perioperative risks associated with many comorbidities present in the geriatric population, reconstruction with small local flaps is 
easily possible after excision.

Compliance with ethical standards

\section{Conflict of interest}

The authors declare that they have no competing interests.

\section{Financial disclosure information}

No financial disclosures.

\section{Ethical standards}

\section{REFERENCES}

1. Burton KA, Ashack KA, Khachemoune A. Cutaneous squamous cell carcinoma: A review of high-risk and metastatic disease. Am J Clin Dermatol. 2016;17(5):491-508. (PMID: 27358187).

2. Situm M, Buljan M, Bulat V, Lugovic Mihic L, Bolanca Z, Simic $D$. The role of UV radiation in the development of basal cell carcinoma. Coll Antropol. 2008;32(2):16770. (PMID: 19138022).

3. Padgett JK, Hendrix JD. Cutaneous malignancies and their management. Otolaryngol Clin North Am. 2001;34(3):523-53. (PMID: 11447001).

4. Zou $Y$, Zhao $Y, Y u$ J, et al. Photodynamic therapy versus surgical excision to basal cell carcinoma: meta analysis. J Cosmet Dermatol. 2016;15(4):374-82. (PMID: 27363535).

5. Walker P, Hill D. Surgical treatment of basal cell carcinomas using standard postoperative histological assessment. Australas J Dermatol. 2006;47(1):1-12. (PMID: 16405477).

6. Sreekantaswamy S, Endo J, Chen A, Butler D, Morrison L, Linos E. Aging and the treatment of basal cell carcinoma. Clin Dermatol. 2019;37(4):373-8. (PMID: 31345326).

7. Yaldiz M. Dermatological diseases in the geriatric age group: Retrospective analysis of 7092 patients. Geriatr Gerontol Int. 2019;19(7):582-5. (PMID: 30950155).

8. Rao JK, Shende KS. Overview of local flaps of the face for reconstruction of cutaneous malignancies: Single institutional experience of seventy cases. J Cutan Aesthet Surg. 2016;9(4):220-3. (PMID: 28163451).

9. Fattahi TT. An overview of facial aesthetic units. J Oral Maxillofac Surg. 2003;61(10):1207-11. (PMID: 14586859).
All procedures performed in studies involving human participants were in accordance with the ethical standards of national research committee and with the 1964 Helsinki declaration and its later amendments or comparable ethical standards.

\section{Informed consent}

Informed consent was obtained from all individual participants included in the study.

10. Miller DL, Weinstock MA. Nonmelanoma skin cancer in the United States: incidence. J AM Acad Dermatol. 1994;30(5):774-8. (PMID: 8176018).

11. Rubin $\mathrm{Al}$, Chen $\mathrm{EH}$, Ratner D. Basal cell carcinoma. $\mathrm{N}$ Engl J Med. 2005;353(21):2262-9. (PMID: 16306523).

12. Albert A, Knoll MA, Conti JA, Zbar RIS. Nonmelanoma skin cancers in the older patient. Curr Oncol Rep. 2019;21(9):79-88. (PMID: 31359294).

13. Rowe DE, Carroll RJ, Day CL Jr. Prognostic factors for local recurrence, metastasis, and survival rates in squamous cell carcinoma of the skin, ear, and lip, implications for treatment modality selection. J Am Acad Dermatol. 1992;26(6):976-90. (PMID: 1607418).

14. Kim JYS, Kozlow JH, Mittal B, Moyer J, Olenecki T, Rodgers P. Guidelines of care for the management of cutaneous squamous cell carcinoma. J Am Acad Dermatol. 2018;78(3):560-78. (PMID: 29331386).

15. Losquadro WD. Anatomy of the skin and the pathogenesis of nonmelanoma skin cancer. facial plast Surg Clin North Am. 2017;25(3):283-9. (PMID: 28676156).

16. Dalal AJ, Ingham J, Collard B, Merrick G. Review of outcomes of 500 consecutive cases of non-melanoma skin cancer of the head and neck managed in an oral and maxillofacial surgical unit in a District General Hospital. Br J Oral Maxillofac Surg. 2018;56(9):805-9. (PMID: 30219606).

17. Ozturk K, Gode S, Erdogan U, Akyildiz S, Apaydin F. Squamous cell carcinoma of the lip: survival analysis with long-term follow-up. Eur Arch Otorhinolaryngol. 2015;272(11):3545-50. (PMID: 25467011).

18. Zitelli JA, Fazio MJ. Reconstruction of the nose with local flaps. J Dermatol Surg Oncol.1991;17(2):184-9. (PMID: 2002164). 
19. Hayano SM, Whipple KM, Korn BS, Kikkawa OD. Principles of periocular reconstruction following excision of cutaneous malignancy. J Skin Cancer. 2012;2012:1-14. (PMID: 23316367).

20. Czyz CN, Cahill KV, Foster JA, Michels KS, Clark CM, Rich NE. Reconstructive options for the medial canthus and eyelids following tumor excision. Saudi J Ophthalmol. 2011;25(1):67-74. (PMID: 23960904).

21. Kim $\mathrm{YH}$, Yoon HW, Chung $\mathrm{S}$, et al. Reconstruction of cutaneous defects of the nasal tip and alar by two different methods. Arch Craniofac Surg. 2018;19(4):260-3. (PMID: 30613087).

22. Kokkoli E, Shih HS, Spyropoulou GA, Jeng SF. Local free-style perforator flaps in head and neck reconstruction: an update and a useful classification.
Plast Reconstr Surg. 2016;137(6):1863-74. (PMID: 26890505).

23. Shen H, Dai X, Chen J, Wang J, Zhang Z, Cai Z. Modified unilateral pedicled V-Y advancement flap for scalp defect repair. J Craniofac Surg. 2018;29(3):60813. (PMID: 29461376).

24. Burch MB, Chung TK, Rosenthal EL, Schmalbach CE. Multimodality management of high-risk head and neck basal cell carcinoma requiring freeflap reconstruction. Otolaryngol Head Neck Surg 2015;152(5):868-73. (PMID: 25805638).

25. Hughley BB, Schmalbach CE. Cutaneous head and neck malignancies in the elderly. Clin Geriatr Med. 2018;34(2):245-8. (PMID: 29661336). 